\title{
Providing the Stability of the Coefficient of Friction of a Vehicle Disk Brake under Extreme Operating Conditions
}

\author{
Yu. Yu. Osenin ${ }^{a}$, Douma Mansur Al-Makhdi ${ }^{a}$, Yu. I. Osenin ${ }^{a}$, \\ O. V. Sergienko ${ }^{a}$, I. I. Sosnov ${ }^{a}$, and A. V. Chesnokov ${ }^{b, *}$ \\ ${ }^{a}$ Dahl East Ukrainian National University, pr. Sovetskii 59a, Severodonetsk, 93406 Ukraine \\ ${ }^{b}$ NTP Fabrika, Kant Baltic Federal University, ul. A. Nevskogo 14, Kaliningrad, 236016 Russia \\ *e-mail: ACHesnokov@kantiana.ru
}

Received January 6, 2016

\begin{abstract}
The authors propose a method of providing stability of the coefficient of friction of a disk brake. The method is based on the use of combination of friction materials in the force pattern of working elements of a disk brake. These friction materials interact with a brake disk and have individual level of loading. The article theoretically substantiates the possibility of the impact of the integral properties of a combination of friction materials involved in the force interaction on vehicle braking parameters. The reasonability of the proposed method is proved by the results of the experimental research. A brake-pad (lining) design has been developed to implement this method.
\end{abstract}

Keywords: disc brake, brake pad, brake disk, coefficient of friction, rolling stock, friction elements, temperature

DOI: $10.3103 / \mathrm{S} 1068366616030132$

\section{INTRODUCTION}

The safety of open-pit, mining, car, and railway transport depends on the stability and the coefficient of friction level of a friction brake, which, in turn, largely depends on the properties of friction materials. The production nomenclature of friction materials includes several hundreds of items and their world production volume is tens of thousands of tons. In the market of friction materials, there are many firms that deal with their development and production. The world's most famous producers are the following ones: Federal-Mogul, Honeywell (United States) (the business of friction materials is sold to the Federal Mogul Corporation TMD Friction), Becorit (Germany), and Wabtec (United States). Despite high financial costs for the development of new friction materials, there is no friction material for disk brakes that would have fully acceptable performance properties according to the criteria of necessary level and the stability of the coefficient of friction.

Studies in the field of improving brake systems have been performed by scientific groups in many countries. The scientific school of the Russian Academy of Sciences Academician V.I. Kolesnikov (Southern Federal University, Russia) is a leading school in the sphere of the development of analytical mathematical apparatus for solving the heat problem for a friction brake system [1,2].
The increase in the cost of brake pads, which are an expendable material, is undesirable because of their high consumption in transport. Thus, a promising trend is the search for new methods of providing friction properties of disk brakes that meet the current requirements.

In the classic schemes of disk brakes, two friction materials are used: the material of a pad and the material of a disk. The friction characteristics of a disk brake are a function of the properties of materials and the conditions of their power loading [1, 3, 4].

An alternative to the development of new friction materials is providing new properties of a disk brake by combining several working materials in a friction assembly, which does not presuppose a significant change in the design of a brake and means of its control and provides wide possibilities for increasing the coefficient of friction and providing the stability of the braking. To increase the efficiency of the work of a disk brake of a vehicle, it is presupposed to create the individual power loading of each of working elements of a disk brake [5].

Thus, an increase in feasibility characteristics of the braking of a vehicle can be achieved based on the development of a disk brake, in a force pattern of which there is a combination of friction materials that are united in a brake pad design, each one has an individual load level. 
In connection with this, a promising trend is the development of new properties of a disk brake by the use of a combination of materials having different friction properties and individual loading conditions in the force interaction of working elements.

The aim of this work is to develop and substantiate the method for providing the stability of the coefficient of friction of a disk brake by the use of a combination of friction materials in the force pattern, to prove experimentally the efficiency of the proposed method according to the criterion of stability of the coefficient of friction, and to develop the design principles of a brake pad (lining) of a disk brake providing the realization of the method.

\section{MATERIALS AND METHODS OF STUDY}

According to the current ideas about the external friction of solid bodies, the total force of friction is a force consisting of elementary forces that occur in individual friction bonds. In turn, the latter are caused by the molecular-mechanical interaction on microcontacts, which are observed on the contact surface of friction elements.

The total outer friction force can be presented in the form of a sum of two components: molecular and mechanical ones, which are interrelated, and their addition for the determination of the total force of friction can be used as the first approximation $[3,4]$.

It is known that the molecular-mechanical interaction of friction elements is caused by the individual properties of materials operated under the conditions of the power loading and under the impact of the environment. Taking it into account, a new method of providing the friction properties of a tribological friction assembly was proposed based on the use of several friction materials in the force pattern of their interaction. The schematic diagram of this method (by example of a disk brake of the rolling stock) is shown in Fig. 1. A brake disk interacts with several friction materials A, B, C, and D, which have different individual properties and loading conditions [5].

According to this scheme, the integral properties of a disk brake are determined by the individual properties of the friction materials A, B, C, and D, the properties of the material of a brake disk 1 , the conditions of their individual loading, and the physical and chemical state of the contact surfaces. In this case, the integral force of friction is equal to the forces of friction occurring at the interaction of each of friction materials with a brake disk.

The thermal interaction of working elements of a disk brake, which contains several friction materials in the force pattern, is illustrated by the differential equation of heat conduction (Fourier-Kirchhoff) presented in a cylindrical coordinate system without inner

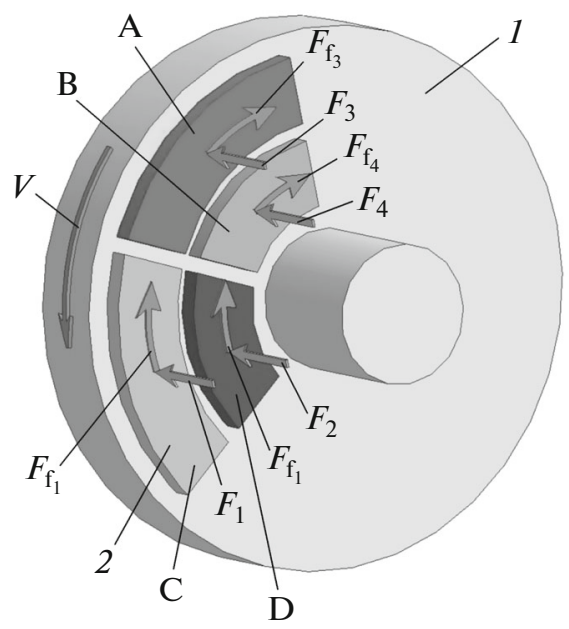

Fig. 1. Schematic diagram of the new method of providing the friction properties of a disk brake of the rolling stock: $\mathrm{A}, \mathrm{B}, \mathrm{C}$, and $\mathrm{D}$ are the materials having different friction properties; 1 -brake disk; $F_{1}, \ldots, F_{4}$ are the optimal loading forces; $F_{\mathrm{f} 1}, \ldots, F_{\mathrm{f} 4}$ are the friction forces.

heat sources [6,7]. The corresponding calculation scheme is shown in Fig. 2.

$$
\frac{\partial T}{\partial \tau}=\vartheta\left(\frac{\partial^{2} T}{\partial r^{2}}+\frac{1}{r} \frac{\partial T}{\partial r}+\frac{1}{r^{2}} \frac{\partial^{2} T}{\partial \varphi^{2}}+\frac{\partial^{2} T}{\partial z^{2}}\right) .
$$

Equation (1) is supplemented by the boundary value conditions. For the side (cylindrical) and end (plane) surfaces of a brake disk, we have the following type- 3 boundary value conditions (without inner heat sources) in Eqs. (2) and (3), respectively:

$$
\begin{gathered}
\pm \lambda\left(\frac{\partial T}{\partial r}\right)=\alpha_{r}\left(T-T_{a}\right), \quad r=R \\
\pm \lambda\left(\frac{\partial T}{\partial z}\right)=\alpha_{z}\left(T-T_{a}\right), \quad z= \pm \delta / 2
\end{gathered}
$$

where $\lambda$ is the coefficient of thermal conductivity and $\alpha_{r}, \alpha_{z}$ are the heat transfer coefficient between the corresponding surface of a brake disk and the ambient air.

For the sliding contact zone surfaces of a brake disk with linings, we have the following type- 4 boundary value conditions with a surface heat source:

$$
\left.\begin{array}{l}
-\lambda_{1}\left(\frac{\partial T_{1}}{\partial z}\right)=\alpha_{\mathrm{fe}} q-\frac{1}{R_{c}}\left(T_{1}-T_{2}\right), \\
\lambda_{2}\left(\frac{\partial T_{2}}{\partial z}\right)=\left(1-\alpha_{\mathrm{fe}}\right) q+\frac{1}{R_{c}}\left(T_{1}-T_{2}\right),
\end{array}\right\}, \quad z= \pm \delta / 2,
$$

where $R_{c}$ is the thermal contact resistance $[8,9]$. Hereinafter, the index 1 refers a value to a brake disk while index 2 corresponds to the brake lining (pad). 


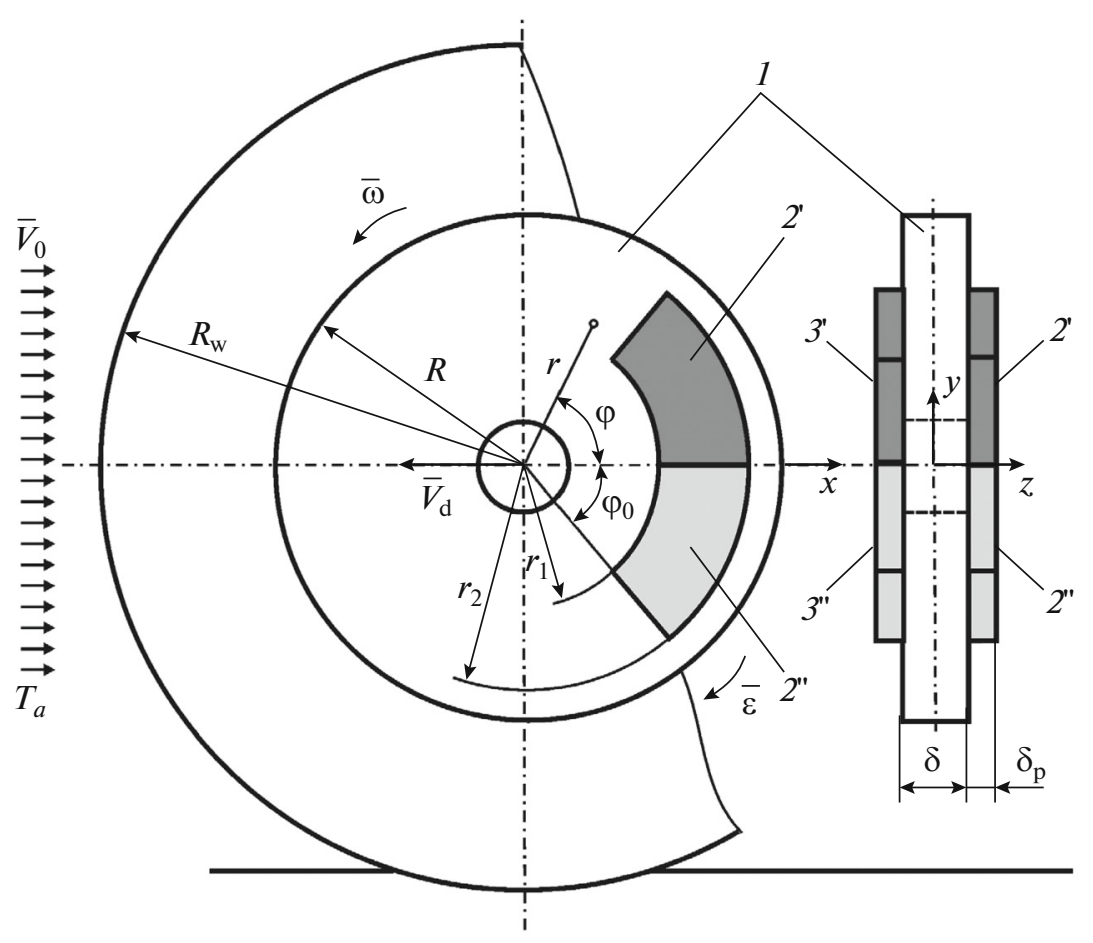

Fig. 2. Estimated scheme of a disk brake of the rolling stock: 1 -brake disk; 2, 3. brake pads; $R, R_{\mathrm{w}}$ is the radius of a brake disk and a wheel; $\delta, \delta_{\mathrm{p}}$ is the thickness of a brake disk and a lining, respectively; $V_{0}$ is the oncoming airflow rate; $T_{a}$ is the average ambient temperature; $V_{d}$ is the current linear speed of a vehicle; $\omega$ is the angular velocity of a brake disk; $\varepsilon$ is an angular acceleration (deceleration) of a brake disk.

The specific heat flow rate generated at the braking by one of the types of friction material (in the condition 4) is as follows:

$$
q(\varphi, r, \tau)=\frac{\alpha_{\mathrm{fe}}}{n_{k} \iint_{s} r(\varphi) d s} \frac{m R_{\mathrm{w}}^{2} \varepsilon}{n_{n}} r(\varphi)\left(\omega^{*}-\varepsilon \tau\right)
$$

To determine the heat-transfer coefficients, the following criterial equations are used in the conditions (2) and (3), respectively:

$$
\begin{gathered}
\mathrm{Nu}_{r}=0.037\left(\operatorname{Re}_{a}^{0.8}+\operatorname{Re}_{\omega}^{0.4}\right) \operatorname{Pr}^{0.33} ; \\
\mathrm{Nu}_{z}=0.135\left[\left(0.5 \operatorname{Re}_{\omega}^{2}+\operatorname{Re}_{a}^{2}+\mathrm{Gr}\right) \operatorname{Pr}\right]^{0.33} .
\end{gathered}
$$

Using the above equations, the following mathematical model of the temperature field of the surfaces of a brake disk was developed:

$$
\begin{gathered}
T^{*}\left(r^{*}, z^{*}, \Theta\right)=q \sqrt{\frac{\delta}{2 R}} \frac{\sqrt{A}+B}{\pi \sqrt{A}+B\left(\pi-2 \varphi_{0}\right)} \\
\times\left[\frac{2 \varphi_{0}}{\sqrt{A}+B} \exp \left(-\sqrt{\frac{2 A R}{\delta}}\left(1-r^{*}\right)\right)\right. \\
+\frac{1}{P} \sqrt{\frac{\delta}{R r^{*}}} \sum_{\alpha_{\mathrm{fe}}=-\infty}^{\infty} \frac{\sin \left(2 \alpha_{\mathrm{fe}} \varphi_{0}\right)}{\alpha_{\mathrm{fe}}} \exp \left(2 P R \frac{\sqrt{\alpha_{\mathrm{fe}}}}{\delta}\left(r^{*}-1\right)\right) \\
\left.\times \cos \left(2 \alpha_{\mathrm{fe}} \Theta+\frac{\pi}{4}-P \frac{2 R \sqrt{\alpha_{\mathrm{fe}}}}{\delta}\left(r^{*}-1\right)\right)\right],
\end{gathered}
$$

where $T^{*}=\left(T-T_{a}\right) / T_{a} ; r^{*}=r / R, z^{*}=2 z / \delta ; \tau^{*}=\omega \tau$; $\Theta=\varphi-\tau^{*} ; P=\omega c_{p} \rho \delta^{2} /(4 \lambda) ; A=\alpha_{z} \delta /(2 \lambda) ; B=\alpha_{r} R / \lambda$.

To calculate the coefficient of friction in the case of the simultaneous use of several $(n \geq 2)$ different friction materials in a brake lining (pad), the following dependence was obtained:

$$
f=\frac{1}{3 N R_{m}} \sum_{i=n}^{n}\left\langle\left(\varphi_{2}^{2}-\varphi_{1}^{2}\right)\left[\left(r_{2}^{3}-r_{1}^{3}\right)\left(f_{m} P_{n}+\frac{0.84 v(v-1) h^{0.5} k N^{\frac{2 v+1}{2 v}} 2^{\frac{2 v+1}{2 v}}}{\pi R_{h}^{0.5} H B^{0.5 / v} b^{0.5 / v}}\right)\right]\right\rangle_{i} .
$$

Together, the above mathematical models make it possible to determine the total value of the coefficient of friction of a friction brake of the rolling stock obtained as the integral value of the combined action of several friction materials with different properties and loading conditions that are simultaneously located on a lining (pad) of a disk brake. 

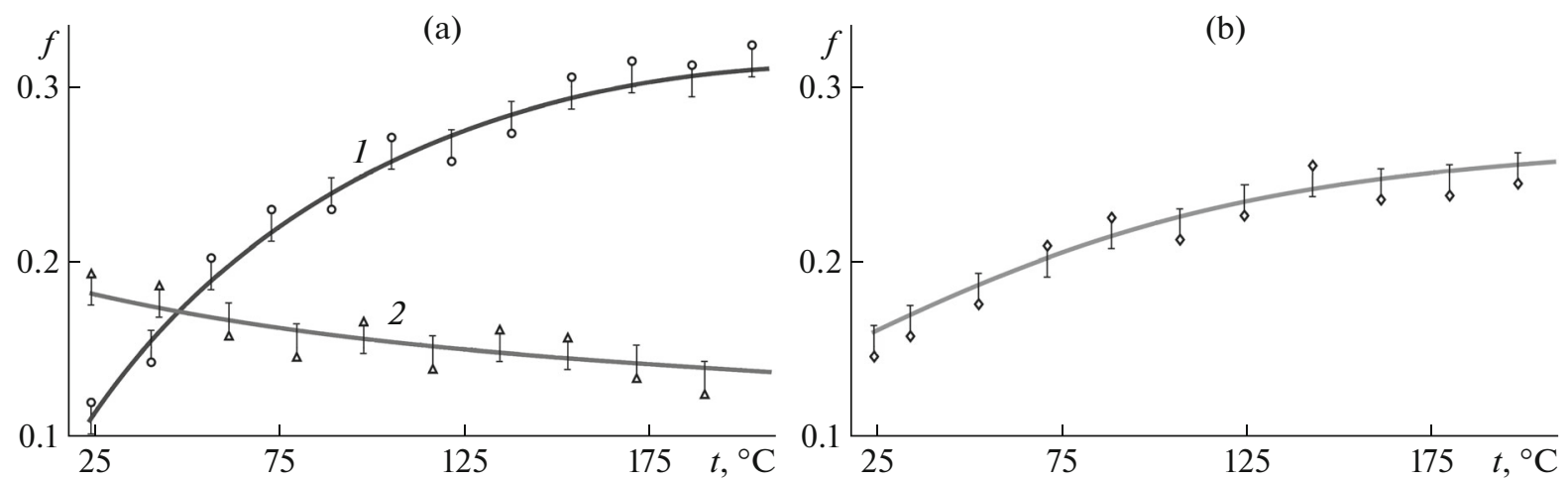

Fig. 3. Dependence of the coefficient of friction on the average temperature of a contact surface of element of a disk brake: (a) (1) carbon-steel combination; (2) cast iron-steel combination; (b) field of values for a carbon-steel-cast iron combination.

The efficiency of providing the integral friction properties of a disk brake based on individual properties of elements of the system and the conditions of their optimal loading are proved experimentally.

Experimental testing was performed using a special test bench designed to simulate the force interaction of elements of a disk brake in real time, acting forces, relative velocities, and heat flows between the friction elements of a brake system. The basis of the test bench is a disk brake of a tram [10]. During the experiments, the following values were controlled: the rotational speed of a brake disk, the pressing force of friction elements, the friction force, and the temperature in the contact zone. The friction materials for the studies were taken so that their characteristics significantly differed according to the criterion of the influence of the temperature: a composite based on carbon fibers (hereinafter referred to as carbon) and gray cast iron (hereinafter referred to as cast iron). Carbon and cast iron together with the material of a steel brake disk formed the following combinations: carbon-steel, cast iron-steel, and carbon-steel-cast iron. The nominal pressure at the contact of the friction elements was $0.5 \mathrm{MPa}$ and the angular velocity of a brake disk was $37.7 \mathrm{rad} / \mathrm{s}$.

\section{RESULTS AND DISCUSSION}

The results of the experiment are shown in Fig. 3. The results obtained in the experiment demonstrated the possibility of providing new friction properties of a friction assembly of a disk brake based on the combination of individual properties of elements of a tribounit and their loading conditions.

The coefficients of friction at the interaction of the carbon-steel and cast iron-steel combinations have the opposite tendencies to change upon an increase in temperature (the coefficient of friction of carbon increases upon the increase in temperature, while that of cast iron decreases). However, upon an interaction of the same elements in the carbon-steel-cast iron combination, the strong tendency of the coefficient of friction to increase upon an increase in temperature with a subsequent decrease in its influence is observed. This combination of materials (carbon-steel-cast iron) has more stable friction properties than those observed in the case of cast iron-steel or carbon-steel materials.

The above results prove the reasonability of the considered method of providing the friction properties of a disk brake based on the combination of individual properties of elements of a tribounit and their loading conditions.

\section{Practical Realization of the Method}

The realization of the proposed method of providing the friction properties of a disk brake presupposes the change in the design of a pad. In this case, the requirements for a brake pad with two working friction materials must be as follows:

- the presence of at least two platforms that are kinematically linked to one another;

- the location of the working materials with different properties on each platform;

-an individual loading level of each of the working materials; and

- the autocompensation of the work of the working materials.

The above requirements are met in the constructive scheme in Fig. 4.

The hinges 3 and 4 provide the distribution of the load of the pads 1 and 2 on the brake disk. An individual loading of the friction materials $\mathrm{A}$ and $\mathrm{B}$ is provided due to different shoulder lengths $C$ and $D$.

A brake pad based on the above scheme is shown in Fig. 4b. The design of a brake pad is protected by a utility patent [11]. 

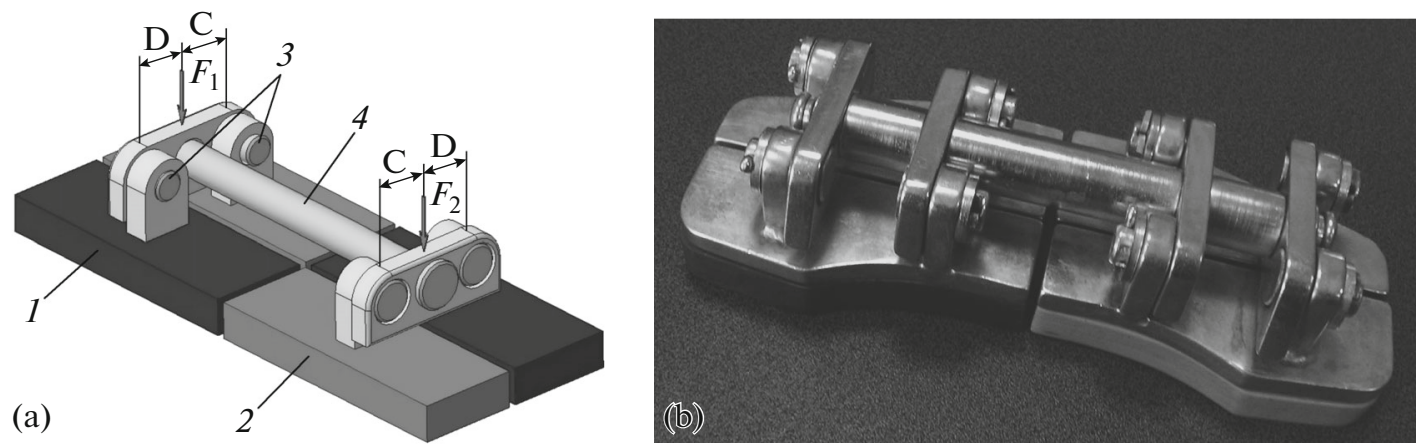

Fig. 4. Scheme of a brake lining of a disk brake (a) and a variant of its practical realization (b): (1) segment where the friction material A is located; (2) segment, where the friction material B is located; $F_{1}, F_{2}$ are the load forces of brake pads; (3) hinges.
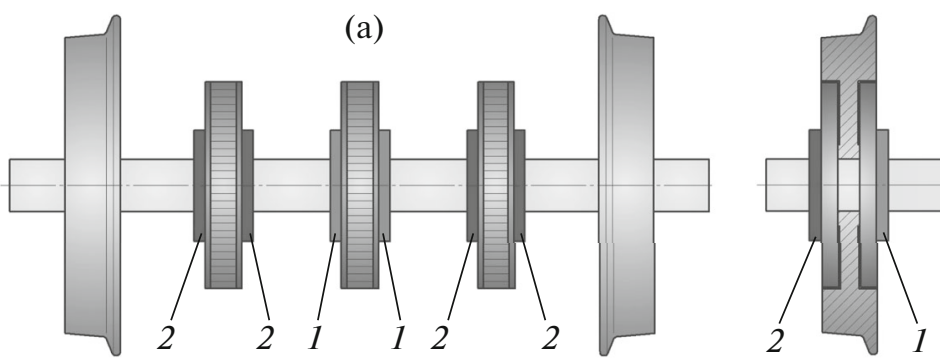

(b)

Fig. 5. Scheme of location of brake linings on wheel pairs (a) with two brake disks and (b) with disks on a wheel center: (1) brake linings with the friction materials A; (2) brake linings with the friction material B.

The presence of the hinges 3 in a pad provides the autocompensation of unequal wear intensities of the friction materials A and B. The presented brake lining is applicable in wheel pairs with one and two brake disks. For wheel pairs with three brake disks and with brake disks fixed on a wheel center, a traditional brake lining on which the friction materials $\mathrm{A}$ and $\mathrm{B}$ are fixed
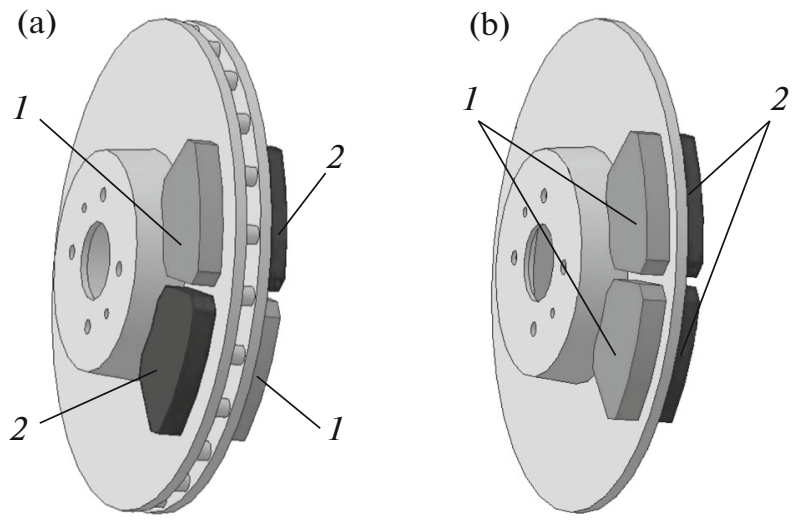

Fig. 6. Scheme of location of brake linings of a disk brake of a car: (a) ventilated disk; (b) nonventilated disk. (1) friction material A; (2) friction material B. can be used. The location of these linings on brake disks of wheel pairs is proposed according to the following schemes (Fig. 5).

A significantly easier method for the development of friction properties of a friction assembly is realized in the design of a pad brake of the rolling stock. In this case, brake pads with different friction materials are located at different sides of a wheel. The optimal pressure of a brake pad on a wheel is achieved by varying the contact surface area.

The realization of the new method applied to a disk brake of a car is shown in Fig. 6. The checkered pattern of brake linings on a ventilated disk of a car is caused by the fact that the friction materials with different properties cause different temperatures during the interaction with a disk. As a result, the surface of a disk can deform in a complex manner under the influence of different temperatures.

\section{CONCLUSIONS}

(1) A method was proposed for providing the stability of the coefficient of friction of a disk brake of a vehicle operated under extreme conditions based on the use of several friction materials in a force pattern of 
their interaction with the consideration of individual loading conditions of each of them. The reasonability of the method was proved experimentally by bench tests.

(2) A mathematical model for the determination of the total value of the coefficient of friction of a friction brake (in particular, a disk brake) of a vehicle was developed as the integral value of a combined action of several friction materials with different properties and loading conditions (in the common case) located simultaneously on a lining (pad) of a disk brake. This occurs with the consideration of the influence of the temperature generated during breaking on the main physical and mechanical properties of materials in the friction interaction. The initial conditions are the values of the temperature of elements of a brake system, the speed of motion of a vehicle, and the oncoming airflow in the moment of time preceding to breaking.

(3) The design of a brake lining that differs from the analogs was developed using two materials with different friction properties. This design of a brake pad provides the following:

- the autocompensation of the wear intensity of one friction material with respect to the other; and rial.

- an individual loading level of each friction mate-

(4) A combination of several friction materials in a force pattern of a disk brake makes it possible to achieve the required performance properties of a disk brake by means of design.

\section{NOTATION}

$\vartheta$

$\tau$

$T$

$\varphi$

$\lambda$

$\alpha_{r}, \alpha_{z}$

$q$

$R_{c}$

$q$

$\alpha_{\mathrm{fe}}$

$m$

$n_{k}$

$n_{n}$

$r$

JOURNAL OF FRICTION AND WEAR

$\omega^{*}$
$\tau_{\mathrm{F}}$
$\operatorname{Re}_{\omega}, \operatorname{Re}_{a}$

angular velocity of a disk $(\varepsilon>0)$

time of breaking (final value)

Reynolds numbers caused by blowing of a break disk with the oncoming airflow

$T^{*} \quad$ dimensionless temperature

$r^{*}, z^{*} \quad$ dimensionless coordinates

$\tau^{*} \quad$ dimensionless time

$c_{p}, \rho$

$f_{m} \quad$ molecular component of the coefficient of friction

$P_{n} \quad$ specific pressure in an assembly of a break disk with a lining (pad)

$N \quad$ normal pressing effort of a lining to a break disk

$H B$ hardness of a material (lowest value in a friction assembly)

$R_{h} \quad$ radius of the curvature of microroughnesses

$R_{m} \quad$ average radius of friction of a break pad

$k \quad$ coefficient depending on geometric and mechanical properties of surfaces

$h \quad$ approaching of contact surfaces of a brake disk and a lining (pad)

$b, v \quad$ parameters of the support surface curve

\section{REFERENCES}

1. Kolesnikov, V.I., Kozakov, A.T., Sidashov, A.V., Kravchenko, V.N., and Sychev, A.P., Diffusion and segregation processes in the metallopolymer tribosystem, J. Friction Wear, 2006, vol. 27, no. 4, pp. 6-9.

2. Sergienko, V.P., Tseluev, M.Yu., Kolesnikov, V.I., Sychev, A.P., Savonchik, V.A., and Yanuchkovskii, V.I., Studying thermal state of friction pairs of multidisc brake, J. Friction Wear, 2013, vol. 34, no. 6, pp. 421428.

3. Spravochnik po tribotekhnike, V3t. - T. 1.: Teoreticheskie osnovy (Handbook on Tribotechnique. In 3 vol., Vol. 1. Theoretical Foundations), Khebda, M. and Chichinadze, A.V., Eds., Moscow: Mashinostroenie, 2000.

4. Garkunov, D.N., Mel'nikov, E.L., and Gavrilyuk, V.S., Tribotekhnika (Tribotechnics), Moscow: KNORUS, 2013.

5. Osenin, Yu., Sosnov, I., and Sergienko, O., Creation method of frictional properties of the disc brake, in Proc. Europe's Braking Conf. and Exhibition "Eurobrake-2013”, Dresden, Germany, 2013, pp. 238-244.

6. Osenin, Yu.Yu. and Sosnov, I., Mathematical modeling unstationary friction interaction of working elements radius vector that describes the contact zone of a disk with a lining 
disc brake locomotive, in Proc. TEKA Commission of Motorization and Power Industry Agriculture and the Volodymir Dahl East-Ukrainian National University of Lugansk, Lublin, 2011, vol. 11B, pp. 111-120.

7. Osenin, Yu., Biloborodova, I., Sosnov, I., and Sergienko, O., Heat abstraction from contact zone of working elements of disc brake, in Proc. TEKA Commission of Motorization and Agriculture, Lublin, Polska Akademia Nauk, 2014, vol. 14, pp. 79-85.

8. Biloborodova, I., Sosnov, I., and Sergienko, O., On contact thermal resistance in the system of active effective cooling of the locomotive disk brake, in Proc. TEKA
Commission of Motorization and Agriculture, Lublin, Polska Akademia Nauk, 2010, vol. 10B, pp. 362-370.

9. Osenin, Yu.Yu., Forced cooling of friction elements of disc brake, in Proc. Europe's Braking Conf. and Exhibition "Eurobrake-2014", Lille, France, 2014, pp. 315323.

10. Osenin, Yu.Yu., Sergienko, O.V., Sosnov, I.I., Bugaenko, V.V., and Pogrebnova, N.E., UKr Patent 79205, Byul., 2013, no. 7.

11. Osenin, Yu.Yu., Sergienko, O.V., Sosnov, I.I., and Bugaenko, V.V., UKr Patent 56777, Byul., 2011, no. 2.

Translated by E. Petrova 